\title{
An Investigation into Staff Behaviour in Unannounced Evacuations of Retail Stores - Implications for Training and Fire Safety Engineering
}

\author{
DMITRY A SAMOCHINE ${ }^{1}$, KAREN BOYCE $^{2}$, and JIM SHIELDS ${ }^{2}$ \\ ${ }^{1}$ Academy of State Fire Service of Russia \\ 4, B. Galushkina St \\ Moscow, 129366, Russia \\ ${ }^{2}$ FireSERT, University of Ulster at Jordanstown \\ Shore Road \\ Newtownabbey, Co Antrim, N. Ireland
}

\begin{abstract}
The behaviour of staff in a fire emergency can have a profound impact on the safety of occupants. This paper presents an analysis of staff behaviour in five unannounced evacuations of Marks and Spencer retail stores. The retail stores participating in the study comprised two three-storey city centre stores and one single storey out-of-town store in different locations in the United Kingdom. The evacuations were video taped using inhouse closed circuit television cameras (CCTV) orientated to cover pre-determined fields of view, and additional, portable cameras which were positioned and concealed when the stores were closed for business on the evenings before the evacuations. This paper presents an analysis of staff behaviour, and consequential impact on customers, as evidenced primarily from the video tapes and questionnaires administered to occupants as they evacuated the store. It was found that staff responses to the alarm, both in terms of time and nature of their responses, varied depending on the setting they were in and their associated responsibilities. Contrary to their training, they did not always respond immediately by evacuating customers but, in the majority of cases, first sought confirmation of the need to evacuate. They did, however, have a significant impact on customer response, not only in overcoming customers' initial evacuation inertia but also in directing them towards suitable exits. This paper seeks to explain staff behaviour in the context of their training and discusses fire safety training in the context of management as an important consideration in performance based fire safety engineering design.
\end{abstract}

KEYWORDS: staff, evacuation, training, occupancy

\section{INTRODUCTION}

Retail premises can be simple corner shops or be part of complex built environments where retailing is not necessarily the primary function, e.g., airport terminals. It is accepted that in a modern competitive commercial world, national and international retail chains seek to offer diversity and variety in choice. Consequently the customer profiles of, e.g., city centre and urban retail complexes can be very different. What is certain is that retailers, in order to survive, seek to attract as many customers as possible from across the societal spectrum into their premises. In addition, changing trading patterns, accessibility and family friendly environments attract large numbers of customers on a daily basis. Given that many retail premises are extremely complex, wayfinding in normal situations, and evacuation in an emergency can be not without its inherent difficulties. Hence, in a fire emergency, retail premises have the potential for multiple fire fatalities and casualties. 
From analysis of case studies related to fire fatalities in retail premises [1,2], it is clear that the principal reason for the occurrence of fatalities was the delay in commencement of evacuation of the occupants. Furthermore, the delay in commencing evacuation of the premises was due to delays in raising a general fire alarm - i.e., the occupants did not know there was a fire until it was virtually too late. In many cases staff alerted managers instead of activating the general fire alarm or wasted time trying to fight a fire that they were not trained to cope with; staff were unable to manage the evacuation, either because they had inadequate fire safety training or were unable to transfer this training into appropriate actions in the event of the emergency.

Dependence on retail staff to overcome customer evacuation inertia has been assumed for buildings which are designed, constructed and managed under prescriptive building regulations. Approved Document B [3], for example, states that it has been written 'on the assumption that the building concerned will be properly managed.' However, the role of staff in a fire emergency takes on even greater importance in an era which is characterised by so-called performance based fire safety design.

This paper presents the findings of five unannounced evacuations of Marks and Spencer retail stores in Wales and Northern Ireland between 1995 and 2001 [4-7]. A detailed analysis of the response of occupants of four of the stores has been published previously [8]. The focus of this paper will be on the response behaviour of staff as evidenced from video footage of the evacuations and questionnaires distributed to occupants as they evacuated the stores.

\section{Theory of Occupancy}

In order to comprehend staff behaviours which may be associated with a developing fire emergency, a theoretical underpinning is necessary. The theory of "occupancy" as articulated in $[9,10,11]$ is proposed and in this context is defined as "the constraints on, conditions and possibilities of knowledge and actions afforded by the social, organisational and physical locations occupied by people over time.” The theory of occupancy introduces a people-environment paradigm where the setting may exert influences on the behaviour of the occupants in the particular setting. Consequently, complex retail premises may be viewed in terms of a diverse set of mini occupancies, e.g., crèches, coffee shops, restaurants, beauty parlours, changing rooms, customers' services and till counters, etc, with each setting imposing different constraints on the occupants, especially the staff. Consider a changing room where the setting is occupied by people of mixed abilities, trying on garments - how are staff likely to respond to a fire alarm? Are their actions predictable? Will appropriate training influence their actions? Will the setting itself influence staff behaviours?

The static setting, which may be a mini occupancy of a large retail complex, is also an informational system within a particular social setting. If fire is introduced, the setting becomes more complex and may be changing rapidly. In this environment, staff actions are crucial in ensuring an efficient and effective evacuation of the premises. The influence of the setting will be explored in this paper.

\section{Staff Training}

The behaviour of staff in an emergency, however, must be considered against the contextual backcloth of the organizational training environment, i.e., it is reasonable to assume that staff response, to a greater or lesser extent, is dependent upon the nature of the training that they have received in relation to fire safety. Marks and Spencer training 
is set out in their policy document [12] and is manifested through a video shown at induction , subsequent refresher training, a guided tour of fire related facilities within the store, and regular fire evacuation drills. The induction video provides a basic introduction to how fire safety is managed in the company, fire prevention, what to do on discovering a fire, how to use a fire extinguisher and what to do in response to an alarm in the store. Evacuation drills are normally conducted in the morning before the store opens or in the evenings, i.e., they are conducted in the absence of customers. A record is kept of drills and staff who have participated. The company policy is that $75 \%$ of staff will have taken part in drills within a six month period.

\section{METHODOLOGY}

The four stores involved in this study comprised two city centre three-storey (basement, ground and first floor) and two out-of-town single storey Marks and Spencer stores. One of the three-storey stores, i.e., Royal Avenue Store in Belfast, was evacuated on two occasions, in 1995 and 2001. The preparations for, and execution of the evacuations, which included informing and liaising with the emergency services and the provision of first aid cover, were conducted without the prior knowledge of the public and store staff, with the exception of the store managers, their deputies and designated safety officers. The evacuations were conducted on Thursday/Friday afternoons at 1500 hrs, i.e., on days and times, deemed from an analysis of departmental sales data by time and day of the week, to represent relatively busy periods in each of the stores. The means of alerting occupants in each store was via an alarm bell. The evacuations were recorded on video tape using existing closed circuit television (CCTV) facilities and additional, concealed, portable video cameras. Existing CCTV cameras were repositioned prior to the evacuations to provide extensive coverage of the sales floor focal areas, e.g., banks of tills, shop floor, circulation routes, exits and changing rooms. Portable cameras were strategically placed and concealed by researchers when the stores were closed on the evenings prior to the evacuations. Information was also obtained by means of questionnaires administered to evacuees leaving the building. The questionnaires were designed to elicit information considered pertinent in relation to characterising occupants and their escape behaviour. The questionnaires were presented to the customers exiting each store during the evacuations by teams of researchers positioned at each exit. The numbers of customers and evacuation times for each of the stores is given in Table 1.

Table 1. Number of customers and evacuation times for each store.

\begin{tabular}{|c|c|c|}
\hline Store & $\begin{array}{c}\text { No. of } \\
\text { Customers }\end{array}$ & $\begin{array}{c}\text { Evacuation Times } \\
\text { (secs) }\end{array}$ \\
\hline Royal Avenue, Belfast (1995) & 571 & 240 \\
\hline Queen Street, Cardiff & 616 & 210 \\
\hline Sprucefield, Lisburn & 477 & 165 \\
\hline Culverhouse Cross, Cardiff & 409 & 131 \\
\hline Royal Avenue, Belfast (2001) & 502 & 255 \\
\hline
\end{tabular}

The video tapes of the five Marks and Spencer evacuations, together with the questionnaires, were analysed to determine staff pre-movement time, staff response to the alarm, and staff impact on customers' evacuation. In so doing, and in order to explore the concept of occupancy, it was decided that consideration would be given to staff 
behaviour in five different settings, which were chosen to represent different environments within the retail store. These were:

- Changing Rooms: staff are in close proximity to customers and have very clear responsibilities; the location of changing rooms mean that they may have minimal field of view to the rest of the store;

- Customer Services: staff have clear duties with respect to serving customers, and in each of the stores were located in areas with little or no aspect to the rest of the store; customer service staff in Marks and Spencer also have additional fire duties which include telephoning the fire brigade, and collecting a first aid box;

- Till Banks: staff are in close and continual contact with customers, and may be reluctant to discontinue serving customers; they also have responsibilities with regard to cash;

- Coffee Shop: staff are serving and waiting on customers; they have well defined responsibilities; they may be influenced by customer behaviour in terms of reluctance to cease their activity;

- Shop Floor: staff have less well defined responsibilities and have little or no direct contact with customers.

\section{The Sample}

Although, a large number of staff were in the retail stores during the evacuation, it was only possible to determine the behaviours of staff who were in the video frame on the sales floor when the alarm sounded, and for whom clear indication of their actions could be discerned. From the videotapes it was possible to observe the behaviour of 102 staff. This represents approximately $30 \%$ of the total number of staff participating in the evacuations. The staff observed were predominantly female (92\%), which is typical of Marks and Spencer sales personnel staffing profile [13]. Table 2 gives a breakdown of the staff observed by setting.

Table 2. Breakdown of staff captured on video by setting.

\begin{tabular}{|l|c|c|}
\hline \multicolumn{1}{|c|}{ Working area } & Frequency & Percentage, \% \\
\hline Changing room & 10 & 9.8 \\
Coffee shop & 6 & 5.9 \\
Customer service & 12 & 11.8 \\
Shop floor & 24 & 23.5 \\
Tills & 50 & 49.0 \\
\hline Total & 102 & 100.0 \\
\hline
\end{tabular}

From Table 2, it is apparent that the numbers of staff observed in the coffee shop, customer service and changing rooms are relatively small. This is reflective of the fact that only one of the five stores had a coffee shop and that less staff are usually allocated to changing rooms and customer services than other settings. The percentages therefore are generally reflective of the distribution of staff within the retail store environment.

\section{RESULTS}

\section{Staff Pre-movement Time}

A common term used in the fire related literature is the pre-movement time (also known as a delay time to start [14] or pre-evacuation activity time (PEAT) [11]. Pre-movement time has been defined as the "time interval between the warning of fire being given (by 
an alarm or by direct sight of smoke or fire) and the first move being made towards an exit" [15]. In the context of this analysis, staff pre-movement time is defined as "the time interval between the warning of fire being given i.e., the alarm and positive evacuation activities by staff". These activities could be, for example, open an emergency exit or direct customers to exit. Descriptive statistics for the pre-movement time of 92 staff, observable from the video tapes of the evacuations, are given in Table 3.

Table 3. Descriptive statistics for staff pre-movement time.

\begin{tabular}{|l|c|}
\hline \multicolumn{1}{|c|}{ Statistic } & Time (secs) \\
\hline Mean & 18.1 \\
\hline Median & 17.0 \\
\hline Standard Deviation & 12.4 \\
\hline Minimum & 2.0 \\
\hline Maximum & 57.0 \\
\hline
\end{tabular}

From Table 3, it can be seen that the mean staff pre-movement time across all settings and stores was 18.1 secs. This value is similar to data presented in [16] for a smaller sample of staff (34) involved in Marks and Spencer Queen Street store evacuation in 1997. This mean pre-movement time is also approximately half of the mean premovement time determined for customers in four of the five evacuations [8]. This indicates that staff responded fairly rapidly to the fire alarm but that there was a further delay in initiating customers' evacuation.

A breakdown of the pre-movement time across the different settings identified earlier is given in Table 4.

Table 4. Descriptive statistics of staff pre-movement time across the settings.

\begin{tabular}{|l|c|c|c|c|c|}
\hline \multicolumn{1}{|c|}{ Setting } & $\begin{array}{c}\text { Number of } \\
\text { staff observed }\end{array}$ & $\begin{array}{c}\text { Mean } \\
\text { (secs) }\end{array}$ & $\begin{array}{c}\text { Min } \\
\text { (secs) }\end{array}$ & $\begin{array}{c}\text { Max } \\
\text { (secs) }\end{array}$ & $\begin{array}{c}\text { Std. Dev } \\
\text { (secs) }\end{array}$ \\
\hline Changing room & 10 & 13.2 & 2.0 & 24.0 & 8.5 \\
Coffee shop & 6 & 18.3 & 4.0 & 29.0 & 10.9 \\
Customer service & 12 & 26.3 & 10.0 & 45.0 & 14.7 \\
Shop floor & 24 & 5.6 & 2.0 & 21.0 & 4.5 \\
Tills & 50 & 21.2 & 4.0 & 50.0 & 10.4 \\
\hline
\end{tabular}

From Table 4, it can be seen that the pre-movement times vary across the settings. From Table 4 it can be seen that the longest staff mean pre-movement times were obtained for staff working in customer services (mean 26.3 secs) and for staff at tills (mean 21.2 secs). It is also apparent that the mean pre-movement time for shop floor staff was considerably less than in the other settings. The significance of these differences was explored. The Kruskal-Wallis test indicated significant differences across the groups (Chi-square (4) = 38.636, $\mathrm{P}<0.001)$. Post-hoc tests indicated significant differences between shop floor and customer service $(\mathrm{P}<0.001)$, shop floor and tills $(\mathrm{P}<0.001)$ with a trend difference between shop floor and coffee shop $(\mathrm{P}=0.055)$.

It seems therefore that setting is influencing staff response to the alarm. It is probable that the main factor delaying the pre-movement time for staff on the tills or customer services is that they are serving customers, and cannot cancel their activity immediately. In contrast, staff on the shop floor have no well-defined responsibilities for customers, i.e., customers are not pressing them to process a transaction, and they are free to respond 
more rapidly to an emergency situation. It would seem that the actual process of customer serving and the constraints that this imposes generates longer pre-movement times.

\section{Staff Response to Alarm}

The required actions of Marks and Spencer staff on hearing the fire alarm are given in their fire safety guidance document [12] and relayed to staff via a video shown at induction. This video suggests that on hearing the alarm, staff should stop serving customers and ask them to leave the store using the nearest exit. Further video clips show staff preventing customers using lifts, and staff and customers leaving the store. Essentially, therefore, staff are required to evacuate customers and evacuate themselves.

The video tapes from the five evacuations were analysed to distil the actions of staff on hearing the alarm. Although an attempt was made to detail all staff behaviour, it was not always possible to trace the entire chain of staff behaviours until they left the store. For example, in many cases, staff exiting one camera shot were not picked up by another camera. However, in all cases it was possible to determine the first staff actions in response to the fire alarm. The actions were categorised as follows:

- $\quad$ Ignore - staff made no visible reaction to the alarm;

- Wait/seek information - staff did not take any positive evacuation action; sometimes they continued to serve customers, sometimes they appeared to be discussing the situation with colleagues; those serving at tills sometimes pressed a button located at the tills which is used during normal activities to attract a manager or supervisor's attention;

- Evacuate customers - staff's response was to initiate the evacuation of customers; the use of staff body language and sometimes voice captured on the video tape enabled identification of the beginning of the customers' evacuation process;

- Evacuate self - this action represents the cases where the staff member could be seen leaving the store;

- $\quad$ Left area - in several cases, on hearing the alarm bell, staff members (sometimes ignoring customers in the area) left the area. The most probable reason for this action is that they were actively seeking further information or alerting, but it is recognized that they could have been evacuating themselves.

The first actions of staff in response to the fire alarm as distilled from the video tapes are given in Table 5.

Table 5. First actions of staff in response to fire alarm.

\begin{tabular}{|l|c|c|}
\hline \multicolumn{1}{|c|}{ Actions } & Frequency & Percentage \% \\
\hline Ignore & 1 & 1.0 \\
Wait/seek information & 62 & 60.8 \\
Evacuate customers & 27 & 26.5 \\
Evacuate self & 1 & 1.0 \\
Evacuate colleagues & 1 & 1.0 \\
Leave area (probably actively seeking information) & 10 & 9.8 \\
\hline Total & 102 & 100.0 \\
\hline
\end{tabular}


From Table 5, it can be seen that there was only one situation where it was absolutely certain that staff completely ignored the fire alarm - the staff member was cleaning a table in the coffee shop and made no visible response to the alarm until she was spoken to by a colleague. From Table 5, it can also be seen that the majority of staff waited for information, usually confirmation from a manager of other colleagues, while $9.8 \%$ undertook, what was likely to be, active investigative actions. Only $26.5 \%$ of staff responded by immediately evacuating customers. In almost all cases, the second action of staff who waited/sought information or ignored the fire alarm was to evacuate customers. Staff who were seen to evacuate customers, often left the frame, so it was not always possible to say exactly what they did next, but it is very likely that they evacuated themselves.

\section{Staff Response to Alarm by Setting}

A breakdown of the response of staff to the alarm by the settings identified previously is given in Table 6.

Table 6. First actions of staff in response to the fire alarm by setting.

\begin{tabular}{|l|c|c|c|c|c|}
\hline \multirow{2}{*}{ Actions } & \multicolumn{5}{|c|}{ Setting } \\
\cline { 2 - 6 } & $\begin{array}{c}\text { Changing } \\
\text { room } \\
\text { \% }\end{array}$ & $\begin{array}{c}\text { Coffee } \\
\text { shop } \\
\text { \% }\end{array}$ & $\begin{array}{c}\text { Customer } \\
\text { service } \\
\text { \% }\end{array}$ & $\begin{array}{c}\text { Shop } \\
\text { floor } \\
\text { \% }\end{array}$ & $\begin{array}{c}\text { Tills } \\
\text { \% }\end{array}$ \\
\hline Ignore & - & 16.7 & - & - & - \\
Wait/seek information & 60.0 & 50.0 & 91.7 & 4.2 & 82.0 \\
Evacuate customers & 20.0 & 33.3 & - & 62.5 & 16.0 \\
Evacuate self & - & - & - & - & 2.0 \\
Evacuate colleagues & - & - & - & 4.2 & - \\
Leave area & 20.0 & - & 8.3 & 29.2 & - \\
\hline Total percentage & 100.0 & 100.0 & 100.0 & 100.0 & 100.0 \\
Total number of staff & 10 & 6 & 12 & 24 & 50 \\
\hline
\end{tabular}

From Table 6, it can be seen that within different settings staff behave in different ways. The most common first action across all settings was to wait/seek information. However, the extent to which this occurred varied across settings with those serving customers, i.e., tills and customer service staff, the most likely to wait for further information/instruction, and those on the shop floor by far the least likely to wait. In general a much larger percentage of staff on the shop floor (62.5\%) evacuated customers as a first action in contrast to staff in other areas, with staff working at tills, being the least likely to evacuate customers. These differences are perhaps not unexpected, since on the shop floor staff have no well-defined responsibilities to customers, unlike staff in other working areas who are directly dealing with customers who are queuing to purchase or exchange goods. It is also important to note that the pre-movement time, reported previously in this paper, is well correlated with the actions taken by staff. Table 4 indicated that the longest pre-movement time was for staff in the customer service department, i.e., the department where the majority (91.7\%) of staff waited/sought information (see Table 6), and that the shortest pre-movement time was for staff who were on the shop floor, i.e., where staff were most likely to evacuate customers as a first action.

The data presented in Table 6 indicates differences in staff response in the various settings. Due to the small sample sizes across the settings, significance testing was 
limited to consideration of differences between shop floor and tills staff. For this purpose, the category 'evacuate self' was combined with the 'evacuate' category. The null hypothesis that there is no difference in the first actions of shop floor and tills staff can be rejected (Chi-Square $=43.26, \mathrm{df}=2, \mathrm{p}<0.001)$.

\section{Staff Impact on Customers' Behaviour}

An estimated 2644 customers were in the stores at the times of the evacuations and the interaction of the majority of them with staff members was captured by the cameras. Staff actions were seen to have an important influence on customers' behaviour, and this was particularly the case in areas where staff had direct contact with customers, for instance tills or changing rooms.

A detailed analysis of the video tapes determined that $79.5 \%$ of staff observed had a direct influence on customers' behaviour. In the large majority of cases, customers did not evacuate until they were told to do so by staff. For the other $20.5 \%$ of staff whose actions were not at any time directed towards evacuating customers, it was possible that this was because their colleagues had already directed customers to exits or there were no customers nearby.

The influence of staff in the early stages of the evacuations was also evident from the questionnaires administered to customers as they left the store. A detailed analysis of customer responses has been given previously in [8]. However the main findings indicate that $46 \%$ of customers across all stores noted that they received their first indication that an emergency was occurring from staff. This compares to 35\% who said it was the alarm that first alerted them, $15 \%$ who noted it was others moving towards exits, and $4 \%$ who noted that they were directly prompted by companions or other customers. It should be noted that during the evacuations, there were no staff announcements to the public by way of public address systems. All communication from staff was given verbally on the floor, either to individuals or groups of customers.

Information was also elicited from the evacuees on factors influencing their choice of exit. An analysis of the questionnaires indicates that $29.5 \%$ of occupants across all stores said that they chose an exit because they were directed to by staff. The percentages ranged from $13.4 \%$ in the Culverhouse store, a single storey store where all but one of the exits were main access points, to $31.1 \%$ in the 3-storey Royal Avenue store. It should be noted that on the questionnaire evacuees were able to give more than one reason for choosing an exit. Other choices offered were that the exit was familiar to them, it was the nearest exit, or that they followed or were directed by others. In providing reasons for exit choice it is recognised that the categories were not mutually exclusive and therefore a customer could have noted that they chose an exit because it was familiar to them and could also have been directed towards it by staff. Notwithstanding, the results indicate the strong influence of staff on exit choice behaviour.

The video analysis also focused on staff behaviour at the latter stages of evacuation, i.e., once the evacuation of most customers had been initiated. This analysis found that many staff continued to influence behaviour by supervising occupant egress flows, checking areas to ensure that they were clear and preventing customers entering the store.

From the analysis of the videotapes it was clear that positive staff actions facilitated swift evacuation, but on the other hand, inappropriate staff response could induce long evacuation delay times. For example, during the evacuation of the Belfast store in 2001, a customer was served by a member of staff for 57 seconds after the fire alarm was 
activated. The data presented earlier regarding first response of staff (Table 5) confirms some of this initial negative staff behaviour, i.e., only $26.5 \%$ of staff evacuated customers as a first action, compared to $60.8 \%$ of staff who waited for further information.

From the video it was also evident that some staff behaviour was strongly influenced by other staff. In general, the situation was very similar to the staff - customer interaction, i.e., some staff did not undertake to do anything until they were told to by their colleagues. It was found, that it was other staff actions which prompted a response for $20.6 \%$ of staff, with higher percentages for staff at tills. This agrees well with the data obtained from a questionnaire administered to staff in the Royal Avenue store 2001 [16] where the actions of other staff were deemed to be the influencing factor for $20.0 \%$ of shop floor staff. This suggests that a core of staff, who can be relied upon to respond appropriately, may be sufficient to initiate evacuation of the premises. Obviously this has implications for fire safety training.

\section{Staff Travel Speed}

In a study by Kholshevnikov [17,18] the link between travel speed and emotional condition of persons was established. It was shown, that all other conditions (age, gender, fitness) being equal, travel speed can be an indicator of the emotional state of a person. It was therefore considered useful to consider travel speed of staff in these evacuations. In determining travel speed, precise distances were difficult to obtain. However, original landmarks were used to determine the approximate distances e.g., floor tiles, known sizes of aisles and shelves. Given that in the later stages of evacuation, staff travel speed was largely dependent on the density of the evacuating customers, this analysis focused on staff travel speed during the first stages after the alarm when staff were able to move freely, initiating the evacuation. All values provided therefore represent unimpeded travel speed.

The travel speed of 47 staff (78.9\% females and $21.3 \%$ males) was calculated and the mean speed determined to be $1.53 \mathrm{~m} / \mathrm{s}$ (range $1.33-2.40 \mathrm{~m} / \mathrm{s}$, s.d. $=0.18$ ). This travel speed is considerably greater than the mean unimpeded travel speed of customers, which was determined to be $1.15 \mathrm{~m} / \mathrm{s}$ (range $0.59-1.90 \mathrm{~m} / \mathrm{s}$, s.d. $=0.22$ ) [4-7]. In many other cases, although it was not possible to quantify the travel speed of staff, it was clear that it was higher than customers' travel speed. It was also established that the average travel speed of male staff was approximately $15 \%$ higher than that of female staff.

Generally, there is a lack of knowledge in fundamental science in the sense of description of emotional state and activity. However, the mean value of staff travel speed in this study i.e., $1.53 \mathrm{~m} / \mathrm{s}$ falls within the "of increased activity" category discussed in $[17,18]$. This category is characterized as follows: "as the increased activity develops, because at this moment the hazard becomes apparent, human actions in terms of speed, acceleration, power increase." This would suggest that some core store staff perceived that an emergency situation was evolving and responded accordingly as evidence by their increased activity.

\section{DISCUSSION AND CONCLUSIONS}

The analysis of the behaviours of staff in five unannounced evacuations of retail stores, presented above, indicates that the behaviours of staff in the event of an emergency can make a significant contribution to the timely evacuation and, hence, life safety potential of occupants. Analysis of these evacuations indicates that almost $80 \%$ of staff had a direct beneficial influence on customer behaviour. In contrast, analysis of fatal fires in 
retail stores [2] confirms that inappropriate staff behaviours can contribute to the loss of life.

Detailed analysis of the five evacuations of retail stores also indicated that the response of staff to the alarm varied significantly with setting. This is fully consistent with the theory of "occupancy" i.e., different settings exert different influences on the occupants which change with time and events. The theory of occupancy facilitates analysis of microoccupancies within a complex environment and furthers the search for greater understanding of human behaviour in fire.

Recent years have witnessed the global transition in developed countries from prescriptive fire safety legislation to functional fire safety regulation based on actual performance of building elements and people in fire. Given the influence that staff have on evacuation, it is clearly necessary that management of the evacuation process is an integral part of any fire safety strategy.

It is considered reasonable to assume that the actions of staff in an emergency would, to a greater or lesser extent, be a manifestation of the organisational training environment to which they belong. Current fire safety training in Marks and Spencer Plc is now beginning to recognize the constraints which settings impose on staff and their associated responsibilities. It is suggested that future fire safety training should be occupancy specific where the particular constraints of identifiable settings are recognized not only when developing evacuation procedures but also within the training environment when instructing staff on the actions to take in an emergency.

Training of course is itself influenced by legislative requirements. Current legislation with regard to Health and Safety at Work in the UK establishes general duties and responsibilities for both the employer and employees. In essence the health and safety requirements are that staff work in healthy and safe environments, that they do not put themselves or work colleagues at risk and that they are trained in the performance of their duties with respect to health and safety at work. Health and Safety legislation however does not expressly require staff to put out fires or to manage the evacuation of the premises in the event of fire. Consequently, fire safety design solutions, incorporating fire safety management as an essential component, require much more than mere compliance with health and safety legislation.

From the results presented in this paper, it is clear that staff intervention had a significant influence on the process of evacuation. However, it was observed that not all staff involved themselves in the evacuation process. Clearly for a successful evacuation to occur, a key group of staff must be involved and have ownership of the process. This means that employers who rely on staff to manage a fire emergency may have to select core staff to play a central role, remunerate them for their additional duties, provide appropriate training recognizing the constraints of occupancy, monitor training and staff performance, update the training to reflect changing needs and perhaps introduce external independent certification [19].

Given the foregoing, it is very clear that performance based fire safety design is not entirely building component driven, but brings into very clear focus the responsibilities of management, the inadequacies of legislation and the need for robust, tailored occupancy specific fire safety training. 


\section{ACKNOWLEDGEMENTS}

The authors gratefully acknowledge the contribution of Marks and Spencer Plc, who willingly made their premises available for, and actively participated in, this study.

\section{REFERENCES}

[1] Bennets, I.D., Poh, K.W., and Thomas, I.R., "Case Studies in Retail Buildings," Fire Code Reform Center, Australia, 1996.

[2] Samochine, D.A., "Towards an Understanding of the Concept of Occupancy in Relation to Staff Behaviour in Fire Emergency Evacuation of Retail Stores," PhD. Thesis, University of Ulster, 2004.

[3] Approved Document B, “The Building Regulations,” ODPM, 2000.

[4] Shields, T.J., Boyce, K.E., and Silcock, G.W.H., "Unannounced Evacuation of Marks and Spencer Sprucefield Store," Cardiff, Client Report to Marks and Spencer Plc., January 1997.

[5] Shields, T.J., Boyce, K.E., and Silcock, G.W.H., "Unannounced Evacuation of Marks and Spencer Royal Avenue Store,” Belfast, Client Report to Marks and Spencer Plc., January 1997.

[6] Shields, T.J., Boyce, K.E., and Silcock, G.W.H., "Unannounced Evacuation of Marks and Spencer Culverhouse Cross Store,” Cardiff, Client Report to Marks and Spencer Plc., January 1999.

[7] Shields, T.J., Boyce, K.E., and Silcock, G.W.H., "Unannounced Evacuation of Marks and Spencer Queen Street Store,” Cardiff, Client Report to Marks and Spencer Plc., January, 1999.

[8] Shields, T.J., and Boyce, K.E., "A Study of Evacuation from Large Retail Stores,” Fire Safety Journal, 35, pp. 25-49, 2000.

[9] Sime, J., "Understanding Human Behaviour in Fires - An Emerging Theory of Occupancy,” Inaugural Lecture, October 14, 1999, University of Ulster.

[10] Shields, T.J., and Boyce, K.E., "Towards Developing and Understanding of Human Behaviour in Fire in Tunnels," Proceedings of the Third International Symposium on Human Behaviour in Fire, Belfast, 2004, pp. 355-366.

[11] Shields, T.J., "Human Behaviour in Tunnel Fires," The Handbook of Tunnel Fire Safety, Chapter 15, Thomas Telford Books, London, to be published 2005.

[12] “Guide to Health \& Safety,” Fire Safety, Marks and Spencer Plc., 2000.

[13] Private Communication, 2004.

[14] Proulx, G., "Movement of People: The Evacuation Timing," SFPE Handbook of Fire Protection Engineering, DiNenno P.J., et al. (eds), NFPA, Massachusetts, 2002, pp. 3-343 - 3-366.

[15] BS 7974:2001, Application of Fire Safety Engineering Principles to the Design of Buildings - Code of Practice, British Standards Institution, 2001.

[16] McClintock, T., "Optimising Exit Choice during Emergency Evacuations from Large Close Environment,” PhD thesis, University of Ulster, 2002. 
[17] Kholshevnikov, V.V., "Human Flows in Buildings, Structures and on Adjoining Territories (in Russian),” Doctor of Science thesis, Moscow, MISI, 1983.

[18] Kholshevnikov, V.V., "The Study of Human Flows and Methodology of Evacuation Standardization (in Russian),” Moscow, MIFS, 1999.

[19] Samochine, D.A., Shields, T.J., and Boyce, K.E., "Development of a Fire Safety Training Tool for Staff in Retail Stores," Proceedings of the Third International Symposium on Human Behaviour in Fire, Belfast, 2004, pp. 355-366. 